
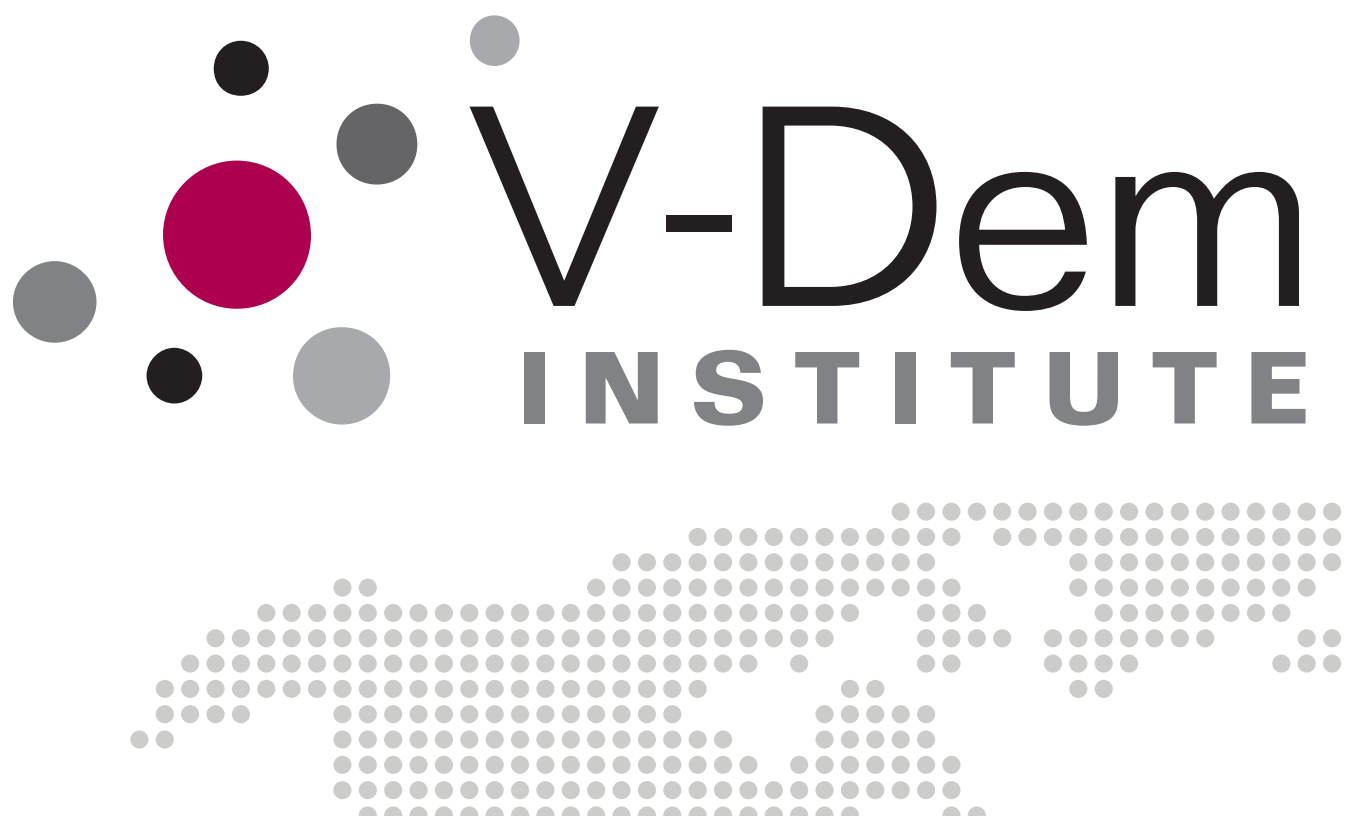

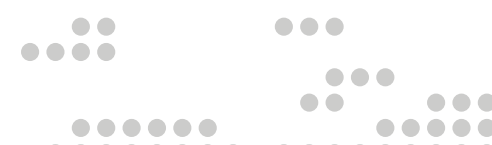

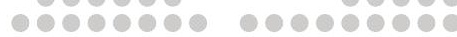
$0000000000000000 \mathrm{c}$

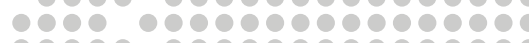

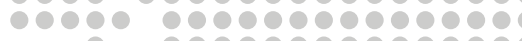

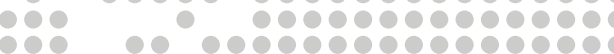

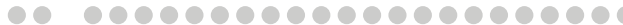

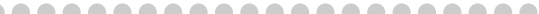

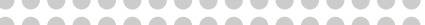
r.680

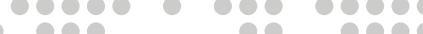

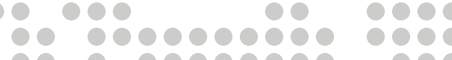
Self-Censorship in Authoritarian States: Response bias in measures of popular support in China

Darrel Robinson Marcus Tannenberg
00000000

60089080

1000000

100000

10000

100

100

10

10

80

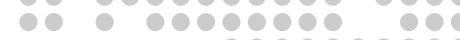

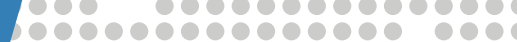

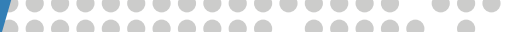

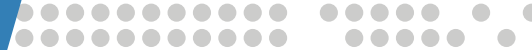

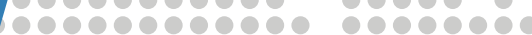

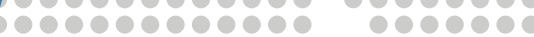
6000000000000000000

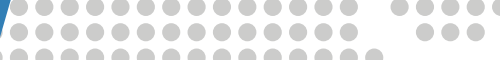

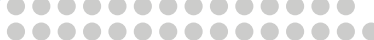
30000000000000000000 10000000000000000000 2000000000000000000

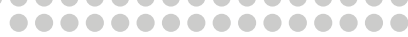

0000000000000

00000000000

0000000000

00000000000

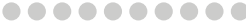

○०00000000е

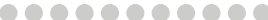

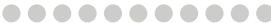

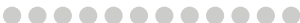

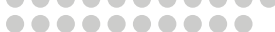

6е890808

000000000

000000

100000

000000

1000

100 :

P

80

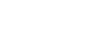


Varieties of Democracy (V-Dem) is a new approach to conceptualization and measurement of democracy. The headquarters the V-Dem Institute is based at the University of Gothenburg with 17 staff, and a project team across the world with 6 Principal Investigators, 14 Project Managers, 30 Regional Managers, 170 Country Coordinators, Research Assistants, and 3,000 Country Experts, the V-Dem project is one of the largest ever social science research-oriented data collection programs.

Please address comments and/or queries for information to:

$\mathrm{V}-$ Dem Institute

Department of Political Science

University of Gothenburg

Sprängkullsgatan 19, PO Box 711

SE 40530 Gothenburg

Sweden

E-mail: contact@v-dem.net

V-Dem Working Papers are available in electronic format at www.v-dem.net.

Copyright (C)2018 by authors. All rights reserved. 


\title{
Self-Censorship in Authoritarian States: Response bias in measures of popular support in China*
}

\author{
Darrel Robinson ${ }^{1}$ and Marcus Tannenberg ${ }^{2}$ \\ ${ }^{1}$ Department of Government, Uppsala University \\ ${ }^{2}$ Department of Political Science, University of Gothenburg
}

April 12, 2018

*For helpful comments, we thank Oscar Almén, Nicholas Kerr, Pierre Landry, Staffan I. Lindberg, Ellen Lust, Kyle Marquardt, Sven Oskarsson, Daniela Stockmann, Katrin Uba, and Samantha A. Vortherms, and Vincent Wen for translation. We are further grateful to Gålöstiftelsen for financial support for data collection. Marcus Tannenberg also wishes to acknowledge support from the Swedish Research Council, Grant 439-2014-38, PI: Pam Fredman, ViceChancellor, University of Gothenburg, Sweden 


\begin{abstract}
The study of popular support for authoritarian regimes, and the comparative study of political attitudes, has long relied on the assumption that survey respondents provide truthful answers on surveys. However, when measuring regime support in closed political systems there is a distinct risk that individuals are less than forthright due to fear that their opinions may be made known to the public or the authorities. In order to test this assumption, we conducted a novel web-based survey in China in which we included four list experiments of commonly used items in the comparative literature on regime support. We find systematic bias for all four measures as a result of selfcensorship; substantially more individuals state that they support the regime with direct questioning than do when presented with our anonymous, indirect list experiments. The level of self-censorship, which ranges from 16 to 22 percentage points, is considerably higher than previously thought. Selfcensorship is further most prevalent among the wealthy, urban, female and younger respondents. These findings indicate that prior studies that have found high levels of support for the Chinese regime using these particular measures likely overestimate the true level of support. Further, crossnational studies which compare popular support across regime type may be systematically biased if responses are not subject to the same level of falsification across regime types.
\end{abstract}


The most elegant way to adjust to censorship is to engage in self-censorship. It is the perfect method for allying with power and setting the stage for mutual exchange of benefit. -Ai Weiwei

\section{Introduction}

In an extraordinary display of public cohesion, as high as $98 \%$ of Chinese survey respondents reported that they had trust in four of the core political institutions at the national level: the Chinese Communist Party (CCP), the national government, the People's Liberation Army and the National People's Congress (Chu et al., 2008). Moreover, in 2003 94\% of respondents stated that "Our form of government is best for us" (Nathan, 2007); and in 2014 president Xi Jinping received the highest approval rating of 30 world leaders (Putin was the runner-up) (Saich, 2014). Compared to almost any country ${ }^{1}$, and certainly relative to any established democracy, these are staggering numbers. But are these expressions of regime support reflective of sincere beliefs?

Given the CCP's consolidation of the national territory and record of economic growth that has lifted people out of poverty at an unprecedented pace (UNDP, 2016), and the regime's focus on good governance and the provision of public goods (Dickson et al., 2016), high support is argued to be a reflection of citizen approval (Holbig and Gilley, 2010; Wang, 2005; Dickson, 2016). Moreover, it has been argued that cultural values in favor of hierarchy and the collective makes the Chinese population predisposed to accept political authority uncritically (Shi, 2008).

It is likely the case that the regime enjoys some level of popular support - it is hard to imagine its survival for such a long period of time without. But there is the distinct possibility that at least part of the explanation to these extraordinary figures lies in the unwillingness of individuals to criticize the regime. China is a one-party state with both the capacity and audacity to carry out mass surveillance, repression, and to root out dissent (King, Pan and Roberts, 2013; Stockmann and Gallagher, 2011). Foreign technology firms such as Google and Facebook that have not agreed to provide user data to the government upon request have been banned from operation (MacKinnon, 2008), and activists, lawyers, and publishers are known to disappear (International, 2016). Perhaps surprising given these concerns, the study of self-censorship in survey data in authoritarian regimes has received little scholarly attention. There are a few notable contributions to this area of research from Russia, China, and a comparative study of African regime types, (cf. Kalinin (2016); Frye et al. (2017); Jiang and Yang (2016) and Tannenberg (2017)), however results have been somewhat inconclusive. In the Chinese context, two recent studies claim to challenge the notion that political wariness, or fear, bias survey results on politically sensitive questions (Lei and Lu, 2017; Stockmann, Esarey and Zhang, 2017). But both of these studies focus in some respect on whether or not individuals react differently to the party (or party members) compared to a purported neutral alternative, not on self-censorship itself. Indeed, Stockmann, Esarey and Zhang (2017) stress that we cannot exclude

\footnotetext{
${ }^{1}$ Notable exceptions are Vietnam (AsianBarometer, 2008) and Russia (Frye et al., 2017; Kalinin, 2016)
} 
the possibility that other sources of bias than political fear distort survey results. As such, it is still unclear if and to what extent Chinese survey respondents self-censor their level of regime support on survey items.

In order to determine if self-censorship is present in Chinese survey data, we conducted an online survey experiment in mainland China. We employ four list experiments to test respondents' support for four potentially politically sensitive propositions: confidence in the national government; belief in the sincerity of an ongoing anti-corruption campaign; preference for the existing system of government; and support for government censorship. The list experiment design works such that respondents' preferences with regards to the sensitive items cannot be traced to an individual while at the same time allowing for estimates of preference for the item at the aggregate level. By providing individual respondents anonymity, we assume that responses from the list experiment technique are more representative of true levels of support than are direct responses. Indeed, list experiments in other contexts have been shown to provide larger estimates of socially undesirable attitudes or behavior (such as prejudice, non-voting, or illicit drug use) than standard, direct techniques (Glynn, 2013) ${ }^{2}$. Estimates from the list experiments are then contrasted to estimates based on direct questions to gauge the extent of self-censorship for each of the four items.

Self-censorship can be differentiated into two distinct methods of hiding one's preferences. The first method is non-response; respondents can simply skip the sensitive survey item, or provide a neutral response. While there are several studies on China that try to infer the sensitivity of a particular survey item by analyzing non- and neutral response (see Lei and Lu, 2017), it is inherently difficult to distinguish between self-censorship and true neutrality. The second method with which one can self-censor is to give a false response - in this case, to state that one supports the regime to a greater extent than one's true belief. The primary focus of a list experiment, and therefore this study, is to estimate the extent of the latter. However, by providing individuals the opportunity to respond anonymously, the propensity to non-respond decreases as well. In fact, non-response to our list items is much less extensive than in the corresponding direct questions, and is comparable in extent to that found in demographic questions such as age, gender, or ethnicity.

The four items we study pertain to political support in the broad sense. We conceptualize political support through the lens of political trust in following Easton (1965)'s seminal work. Easton (1965) differentiates between diffuse support which pertains to the long-standing institutions of the regime, and specific support which pertains to short-term aspects such as actors and particular policies. Our study is designed such that two sensitive items are intended to evaluate diffuse support and two items specific support. Item one pertains to specific support and is a classic survey question which evaluates confidence in the current central government. The second item probes for respondents' perception of a Xi Jinping's flagship anti-corruption campaign that he launched immediately after having assumed office, which resulted in 1.16 million corruption charges filed against officials and has punished 1.2 million out of the party's 88 million members for disciplinary violations (China Daily,

\footnotetext{
${ }^{2}$ A list experiment does however not incentivize truthful responses, it simply removes the risk that one's preferences can be made known.
} 
2017). In addition to the campaign being closely tied to the current top leadership, it is contested if it represents a sincere effort to root out corruption or simply functions as a tool for the elimination of rival factions (for a discussion see $(\mathrm{Lam}, 2015))^{3}$. The item thus functions as a second evaluation of specific support, and support for Xi Jinping in particular.

The third item falls onto diffuse support as it is evaluative of the political regime as a whole, specifically, to what extent an individual believes the current system is best ${ }^{4}$. The fourth item probes for support for a specific institution, namely government censorship. Similar to our third item, we argue that censorship is representative of the diffuse support given that it is such a defining feature of CCP rule. Further, while direction may come from the central government, implementation is done at all levels, and even by private companies which operate in China. Moreover, control (freedom) of the flow of information is a central feature of authoritarian (democratic) politics that warrants its inclusion as a measure of institutional support for authoritarian rule.

In contrast to Stockmann, Esarey and Zhang (2017) and Lei and Lu (2017) studies, our findings indicate that self-censorship is in fact widespread for all four of our sensitive items and considerably higher than previously assumed. The differences between estimates using indirect questioning (list experiment) and those from direct questions are significant and substantial, ranging from 16 to 22 percentage points. Our findings add new insights into public opinion and self-censorship in China and in autocracies in general, and calls into question the comparative use of political survey items that may differ in sensitivity across contexts.

The article proceeds as follows. First we discuss theories of self-censorship in authoritarian countries as well as how previous research in China has viewed this source of bias in Section 2. We then describe our sample in Section 3, followed by a detailed discussion of our estimation strategy using the list design in Section 4. In Section 5 we present our results including estimation of the individual characteristics that predict self-censorship before we present our conclusions in Section 6.

\section{Self-censorship in authoritarian settings}

In all political contexts there is an ever-present risk that survey respondents censor themselves when answering questions that are invasive into private matters (Tourangeau and Yan, 2007). As a result, survey questions relating to income (Chung and Monroe, 2003), voter turnout (Holbrook and Krosnick, 2010), prejudice against other ethnic or religious groups (Kuklinski, Cobb and Gilens, 1997), and drug abuse or other illegal activities (Krumpal, 2013) have all been shown to be subject to self-censorship for reasons of prestige, fear of social sanction from peers for deviation from a

\footnotetext{
${ }^{3}$ While the latter is the popular narrative in the media, recent scholarly work have argued that the campaign has significantly reduced bureaucratic opportunities for graft (Manion, 2016; Wedeman, 2017) and shown that geographically intense social media posts relating to corruption does predict corruption probes (Qin, Strömberg and Wu, 2017) indicating that the campaign is more than a tool in factional politics.

${ }^{4} \mathrm{By}$ regime we refer to a particular form of government or type of political system, and not to the incumbent government, although in the case of China these might be hard to distinguish
} 
perceived social norm, or fear of punishment from the authorities. This poses a serious problem for the study of such topics because it can lead to systematic non-responses, "don't knows", or false answers, all of which distort the quality of the data.

Most pertinent to survey data from authoritarian states is the potential for bias stemming from political fear. Kuran (1997) argues that citizens living in authoritarian regimes have strong incentives to hide their true political preferences - to exercise "preference falsification" - in public simply to stay safe. Criticism of - or even failing to show explicit support for - the regime can provoke repercussions in the form of infringement on personal life, economic exclusion or outright physical repression. With reference to communist Czechoslovakia, Havel (1989: 37) describes a society of veiled preferences in which people control and censor themselves creating a system in which everyone is "both a victim and a supporter", resulting in a situation where rulers and ruled are "living a lie". Because of this risk for self-censorship, there are concerns for the feasibility of obtaining reliable estimates of regime support in authoritarian regimes through the use of public-opinion surveys (Schedler, 1999). This is especially true for questions that demonstrates respondents' compliance with the regime. If there is little or no benefit to the respondents in giving their honest answer, respondents should more likely to self-censor (Corstange, 2009).

However, political fear is not the only explanation as to why self-censorship may exist in the context of an authoritarian regime. Such high levels of explicit support may be a result of social desirability bias in the classic sense of conforming to what one believes to be a social norm. Potential social repercussions may prevent an individual from free expression of regime criticism if they believe that others in their social setting hold regime friendly views, and will socially sanction one for nonconformity (Frye et al., 2017). In this sense, falsely stating regime support in China could be comparable to falsely reporting that one has voted in a democracy.

Research in China and other authoritarian countries has long argued that survey responses are not subject to self-censorship (see Wang, 2006; Kennedy, 2009; Geddes and Zaller, 1989). The justification for this assumption is based on the observation that individuals do express critical viewpoints during qualitative interviews (Li, 2004), or that trust in government only weakly correlates with fear of being reported to the authorities (Shi, 2001; Chen and Shi, 2001), or quite simply because enumerators believed respondents to have expressed sincere beliefs (Geddes and Zaller, 1989). However, these arguments are not unproblematic. For instance, Li (2004) finds that rural (his sample does not include any urban residents) Chinese do criticize the regime, but that it is often directed at local governments, not the center. Criticism that does arise of the center is primarily aimed at its ability to implement its desired policies, not its intentions, which villagers often deem to be benign. Further, to study the correlation between a measure of political fear and political trust as is done in Shi (2001) and Chen and Shi (2001) is potentially problematic because political fear may itself be sensitive ${ }^{5}$. Moreover, while we highlight two possible reasons why individuals may self-censor preference falsification and social desirability bias - this empirical test, whether it is reliable or not,

\footnotetext{
${ }^{5}$ The question reads, "If you criticized the party and state leaders in conversations where you live or work, would you be concerned that someone would report you to the authorities?"
} 
can only rule out one of these pathways.

Recently, researchers have begun to question the assumption of truthful response and subject it to empirical scrutiny, but the findings remain inconclusive. Research on Russia has found that voters over-report their electoral support for President Putin (Kalinin, 2016) but that opinion polls nevertheless reflect actual approval for the president (Frye et al., 2017). Tannenberg (2017) finds using Afrobarometer data that respondents in more autocratic countries systematically report more positive views of citizen-state relations when they believe that a survey was commissioned by the government rather than by an independent organization.

In the Chinese context some creative research designs have been used to test for the existence of self-censorship. Specifically, Jiang and Yang (2016) find that responses to politically sensitive and insensitive survey items diverged around the time of a political purge in Shanghai. But they also find that these effects were short-lived - responses to the sensitive and insensitive items converged again roughly 3 weeks after the initial purge. While their results show that self-censorship obviously increased in this period, it is unclear if baseline (that is, non-purge affected) survey responses are also plagued by self-censorship. Lei and Lu (2017) - in contrast to Tannenberg (2017) - show that there is little difference in survey responses if the enumerator conveys cues of affiliation with the CCP in an experimental study in Sichuan province. This design nevertheless leaves open the possibility that individuals self-censor regardless of enumerator affiliation - the control group was defined as those for "which face-to-face surveys were administered following the standard procedure endorsed by Chinas academic survey industry". That is, the control group received an enumerator affiliated with a university. But as (Jiang and Yang, 2016) point out, local government officials are often used in large survey projects to dismiss concerns among citizens that university-affiliated survey teams lack credibility ${ }^{6}$. And finally, (Stockmann, Esarey and Zhang, 2017) study how affect transfer relates to the likelihood of expressing support for the national government, not self-censorship in itself.

While these studies all provide valuable contributions to the literature on self-censorship, they leave unanswered the fundamental question as to if and what proportion of Chinese respondents selfcensor responses of regime support in a standard, academic survey setting. Our experimental study contributes to this prior work through the introduction of a strong design for the measurement of self-censorship employed to a considerably larger and more geographically diverse sample. Further, we test this proposition with four survey items which map onto two distinct forms of regime support - all of which are common survey items in the comparative literature.

\footnotetext{
${ }^{6}$ As to whether or not our study could potentially lack credibility such that respondents would view the aims as suspect, it should be noted that we collaborated with a local market research firm with which respondents have pre-registered. As initial contact to the survey was made by the market research firm and respondents subsequently opt-in to the survey, concerns of credibility should be lower than if an unsolicited enumerator were to contact one at home.
} 


\subsection{Eliciting truthful responses in authoritarian settings}

One of the most commonly used techniques to allow the researcher to elicit truthful information about sensitive issues is the list experiment (also called Item Count Technique). Political scientists have employed the technique to study sensitive topics such as: race relations (Kuklinski, Cobb and Gilens, 1997); corruption; (Gingerich et al., 2016); vote turnout (Holbrook and Krosnick, 2010); vote buying (Gonzalez-Ocantos et al., 2012); electoral rights (Corstange, 2009); opposition violence (Weghorst, 2011); electoral support (Kalinin, 2016); and approval ratings of autocratic leaders (Frye et al., 2017). List experiments allows respondents to hide their true opinion on a sensitive topic by asking them to indicate the number of items on a list of propositions with which they agree or oppose (Frye et al., 2017), activities in which they engage (Kuklinski, Cobb and Gilens, 1997; Holbrook and Krosnick, 2010), or things that upset them (Kuklinski, Cobb and Gilens, 1997). By asking respondents how many of the items apply to them, instead of which particular items apply to them, respondents can indicate their true opinion on the sensitive topic while retaining ambiguity over their specific opinion on any one given item. Thus, neither the researcher, enumerator, or any other person that may obtain the raw data can identify the specific preference of the respondent, who is therefore expected to feel comfortable to indicate her true opinion with regards to the sensitive item.

In our application, the level of self-censorship can be understood as the difference in the proportion of "regime friendly" responses with direct questioning and the list experiment; where respondents perception of anonymity is not guaranteed to when it is guaranteed (under certain conditions). That is, the difference between support for a sensitive item when asked about it in a typical, direct survey fashion versus indirectly in the context of a list. The viability of the list experiment for the study of socially sensitive topics has been shown in the works of Corstange (2009); Glynn (2013) and Imai (2011), however it is faced with limitations due to its inherent inefficiency and difficulties associated with uncovering individual characteristics which correlate with the sensitive item (Glynn, 2013). Furthermore, its assumption of strict anonymity can be violated through both ceiling and floor effects. The first is an instance when all of the items on a list applies to a respondent and the latter when none of the items apply. The risks associated with these violations can be reduced by increasing the number of items on the list (Holbrook and Krosnick, 2010) and/or including items that are expected to be negatively correlated (Glynn, 2013). When these assumptions hold, the technique provides valid estimates of true support for sensitive items.

\section{The Sample}

The data for the study was collected via a novel web-based survey conducted in Mainland China. A large market research firm in China was contracted to recruit a random sample of respondents from their panel of over 2 million users. Respondents were invited to partake in a short survey on political attitudes and were offered a nominal reward for their participation (6 yuan, approximately 
$\$ 0.85)$. Invites were sent out via email and the survey was both mobile and computer compatible. Those that agreed to participate were directed to a Qualtrics account registered to the researchers. Participants were informed before beginning the survey that the study was being conducted by an independent, foreign research university, with a text including the name and logo of the university, as well as an introduction to the responsible researcher with corresponding contact information. As a quality check we included two control questions in the survey, one in the middle prior to the presentation of the lists and one at the end, to ensure that participants were not simply selecting responses at random ${ }^{7}$. A total of 2463 participants entered the survey which resulted in a sample of 1953 after removing those that did not finish or failed one of the quality checks (for a completion rate of $79 \%$ ). 10,000 invites were initially distributed but the data collection was stopped once we reached 1900 complete responses. The response rate of the survey is therefore unknowable as non-participants among the full sample of invitees represent both those that chose not to complete the survey and those that were slower to respond to the email invitation.

A web-based sample is naturally unrepresentative of the general population with a higher proportion of young, educated, urban and wealthy individuals, particularly in a developing country where far from all can afford access to the Internet. At the time of fielding the survey, China had 731 million Internet users, making up $53.1 \%$ of the population. In comparison, Internet penetration in the US was at $87.9 \%$ and in India 34.4\% (Internet World Stats, 2017). There is a risk that the demographic imbalance can have implications for the level of self-censorship, as it is plausible that some groups are more likely to self-censor than others, a point to which we return in our estimates of the individual level characteristics of self-censorship (see also Jiang and Yang, 2016, for their discussion of the variability of self-censorship). Despite limitations with regards to generalizing to the larger population, evaluations of web-based and crowd-sourcing samples have found that participant pools are much more diverse than other samples of convenience such as university students (Buhrmester, Kwang and Gosling, 2011). Further, our sample is geographically much more representative than are prior studies of political fear in China. While Jiang and Yang (2016); Lei and Lu (2017) and Stockmann, Esarey and Zhang (2017) conduct studies in Shanghai, Sichuan province, and Beijing respectively, our sample consists of observations from all Chinese provinces with a mix of rural and urban respondents (see Appendix 5 for the geographical distribution of respondents).

In democratic countries it has been shown that web-based data collection is more likely than faceto-face interviews to elicit truthful responses to sensitive questions (Heerwegh, 2009; Holbrook and Krosnick, 2010). Rather than reporting a response to an enumerator, who in the case of academic surveys in China is often connected to a state-run university, respondents have the security of recording answers on their own personal devices in a place and time of their choosing with no oversight of an interviewer. On the other hand, web-based surveys in China may not provide the same level of respondent security; censorship of the Internet is so extensive that respondents may be more likely to falsify preferences given that they know that the Internet is monitored. While the

\footnotetext{
${ }^{7}$ For exact wording see survey question number 21, and 31 in Appendix F
} 
Table 1: Study sample comparison to Internet users and a representative sample

\begin{tabular}{|c|c|c|c|c|}
\hline & & Study Participants & Internet Users & WVS 2012 sample \\
\hline \multirow[t]{3}{*}{ Gender } & Male & $49.9 \%$ & $53 \%$ & $50.8 \%$ \\
\hline & Female & $49.9 \%$ & $47 \%$ & $49.2 \%$ \\
\hline & Other & $0.21 \%$ & - & - \\
\hline \multirow[t]{4}{*}{ Region } & Northeast & $6.1 \%$ & $10.1 \%$ & $8 \%$ \\
\hline & Coast & $68.7 \%$ & $46.2 \%$ & $40 \%$ \\
\hline & Central & $12.9 \%$ & $22.1 \%$ & $25.6 \%$ \\
\hline & West & $12.2 \%$ & $21.5 \%$ & $26.4 \%$ \\
\hline \multirow[t]{4}{*}{ Income } & $<=50,000(60,000)$ & $9.8 \%$ & 71.2 & - \\
\hline & $50-100,000(60-100,000)$ & $36.1 \%$ & $11.9 \%$ & - \\
\hline & $>=100,000$ & $47.8 \%$ & $8.4 \%$ & - \\
\hline & No income or no response & $6.3 \%$ & $8.4 \%$ & - \\
\hline \multirow[t]{5}{*}{ Education } & Primary or below & - & $14.3 \%$ & $25.4 \%$ \\
\hline & Junior Secondary & $2.46 \%$ & $37 \%$ & \multirow{2}{*}{$63 \%$} \\
\hline & Senior Secondary & $11.87 \%$ & $28.2 \%$ & \\
\hline & Junior College & $22.16 \%$ & $8.9 \%$ & \multirow{2}{*}{$11.6 \%$} \\
\hline & University or above & $63.21 \%$ & $11.5 \%$ & \\
\hline \multirow[t]{6}{*}{ Age } & $<=19^{*}$ & $1.1 \%$ & $23 \%$ & \multirow{2}{*}{$21.8 \%$} \\
\hline & $20-29$ & $34.1 \%$ & $30.4 \%$ & \\
\hline & $30-39$ & $43.2 \%$ & $24.2 \%$ & \multirow{2}{*}{$46.2 \%$} \\
\hline & $40-49$ & $17.1 \%$ & $13.4 \%$ & \\
\hline & $50-59$ & $3.7 \%$ & $5.3 \%$ & \multirow[t]{2}{*}{$32 \%$} \\
\hline & $>=60$ & $0.08 \%$ & $3.7 \%$ & \\
\hline
\end{tabular}

Note: Internet user data from The 38th Statistical Report of Internet Development in China (July 2016).

Region data from the 37th edition (January 2016). World Values Survey data from Wave 6 (2012). 
primary function of online censors has been to remove content deemed inappropriate by the regime, and only as tool to identify political opponents upon repeated attempts to coordinate collective action (King, Pan and Roberts, 2013), there has been a shift in recent years towards a larger emphasis on identifying influential social media users who challenge the Party's hegemonic position (Miller and Gallagher, 2018).

While we are careful to avoid any claim that our sample is representative, it is a random sample from the market research firm's population which allows us to generalize to this segment of the Chinese population. Further, $81 \%$ of our sample conforms to the definition of Netizens - the segment of the Chinese population that gains information primarily from online sources rather than traditional media. Pertinent to this study, it is well-known that Netizens are more openly critical of the government than are other segments of the population which might make them less likely to self-censor (Lei, 2011). Nevertheless, given our unique sample and web-based data collection, it remains unclear how far these findings can be generalized beyond the market research firm population. While this is a valid concern, the strength of this study is in its experimental design; that is, while the external validity of the study may be low, it has high internal validity.

We present a descriptive comparison of our sample with a representative sample of Chinese Internet users and a World Values Survey sample (intended to be nationally representative, conducted with face-to-face interviews) in Table 1 . The primary difference between our sample and the sample of Internet users is in education level and income, our sample being wealthier and more highly educated. Differences in age result because we restricted our data collection to only individuals above the age of 18 , and differences in region are likely a reflection of the need to start the survey during office hours in Eastern China where the market research firm is located. Therefore, while we have observations from every single Chinese province, the Eastern provinces are overly represented in relation to population size. Our sample is descriptively very similar to other web-based samples in China (see Huang and Yeh, 2017; Truex, 2014).

\section{Design and Estimation}

We conduct four list experiments to test four different aspects of regime support. As we argue above, these four measures represent two distinct dimensions of political support - diffuse support which represents system/institutional support, and specific support for the current leadership (Easton, 1965). Our measures of diffuse, system support include belief that the current system of government is better than others, and support for the government's right to censor the media in order to prevent political instability. We did not include measures of support for individual actors such as President Xi Jinping to investigate support for current leadership as we deemed such statements unlikely to pass online censors. Further, such action would be unethical towards our local partners as they, rather than we, would be subject to any eventual consequences ( $\mathrm{Lu}, 2016)$. Rather, in order to estimate specific support for current leadership we use measures of confidence in the national government and 
belief in the sincerity of an ongoing anti-corruption campaign. The latter is particularly salient as it has been a primary, and highly publicized, policy of Xi Jinping's rule, and was recently reaffirmed at the latest National People's Congress in March 2018.

The four lists are presented below in Table 2. Each list contains five statements with the sensitive item of interest in bold; the statements are arranged in the order in which they were presented to respondents. To minimize the risk that respondents would learn the purpose of the exercise we intentionally varied the positioning of the item of interest in the lists, and chose control list items that were broadly political or social in nature so that the item of interest did not appear too conspicuous. Lastly, to avoid ceiling and floor effects - when a respondent agrees with all or none of the statements thereby exposing their true preference to the sensitive item and invalidating the list experiment - we followed Glynn (2013) and designed the lists to contain at least two items that negatively correlate. We conducted two pilot studies to evaluate and adjust our lists so that ceiling and floor risks would be minimal. From the full distributions of responses for each of the four experiments our approach was successful (see Table 6 in Appendix A). The low number of respondents in the lowest and highest categories should alleviate any concerns about ceiling and floor effects.

In order to ensure the anonymity of responses, individuals are asked to state the number of items from the list with which they agree, but are not asked to identify any specific item. The control group received a list with four statements, all of those excluding the item of interest in bold, and the treatment group received the full list of five statements. Therefore, the only difference between the treatment and control versions was the presence of the sensitive statement of interest for the corresponding list. The response field was a numerical drop-down list from 0 to 5 (0 to 4 for the control groups) so providing a non-numerical answer thereby revealing a preference for a given statement was not possible. It is possible that additional items on the lists, such as "Overall, the country is going in the right direction", are sensitive in the Chinese political context, but because the same items are presented to the control and treatment group, the potential sensitivity of any additional item does not invalidate the results.

The survey included several demographic items such as gender, age, level of education, income, ethnicity, region and city, hukou status, occupation, primary source of information, party membership, and number of children. We further asked for information about parental education and party membership, as well as three measures of authoritarian personality (for the full survey see Appendix F). We use this information to identify individual characteristics that are likely to induce preference falsifying behavior.

\subsection{Design}

The experiment was conducted with two-stage randomization. First, we created two blocks each containing two treatment and two control lists. Block 1 contained treatment lists Confidence and Censorship and the control lists System and Corruption. Block 2 reverses the order and contained the 
Table 2: The List Experiments

\section{Confidence}

Generally speaking, most people cannot be trusted.

We should focus less on the economy and more on the environment.

The government is like a parent and should tell us what to do.

I have confidence in the national government.

The government is the employee of the people and should do things according to the wishes of the people.

Corruption

Air pollution is one of the most important problems in our country.

Overall, the quality of life was better 30 years ago.

Overall, our country is going in the right direction.

The government is doing its best to crack down on corruption and root out bribery.

Economic progress is more important than protecting the environment.

\section{System}

It is important to follow religious norms and ceremonies.

Private ownership of business should be increased.

Our system of government is better than any other that I can think of.

Women make equally good political leaders as men.

When jobs are scarce, men should have more right to a job than women.

Censorship

People can only get rich at the expense of others.

The government should have the right to prevent the media from publishing things

that might be politically destabilizing.

I consider myself capable of participating in politics.

It is reasonable for students to pay tuition for university education.

The economic situation of my family was better a few years ago than it is today. 
treatment lists System and Corruption, as well as the control lists Confidence and Censorship. The blocks were designed such that each block contains one diffuse and one specific support treatment list. Random assignment determined which block respondents received. Each respondent therefore is both in the treatment group for two items and control group for two others. The second-stage was to randomize within the blocks themselves; the order in which the lists were presented to respondents was randomized so as to avoid any potential priming effects that may have arisen from being presented with a treatment (or control) list first.

Figure 1: Design

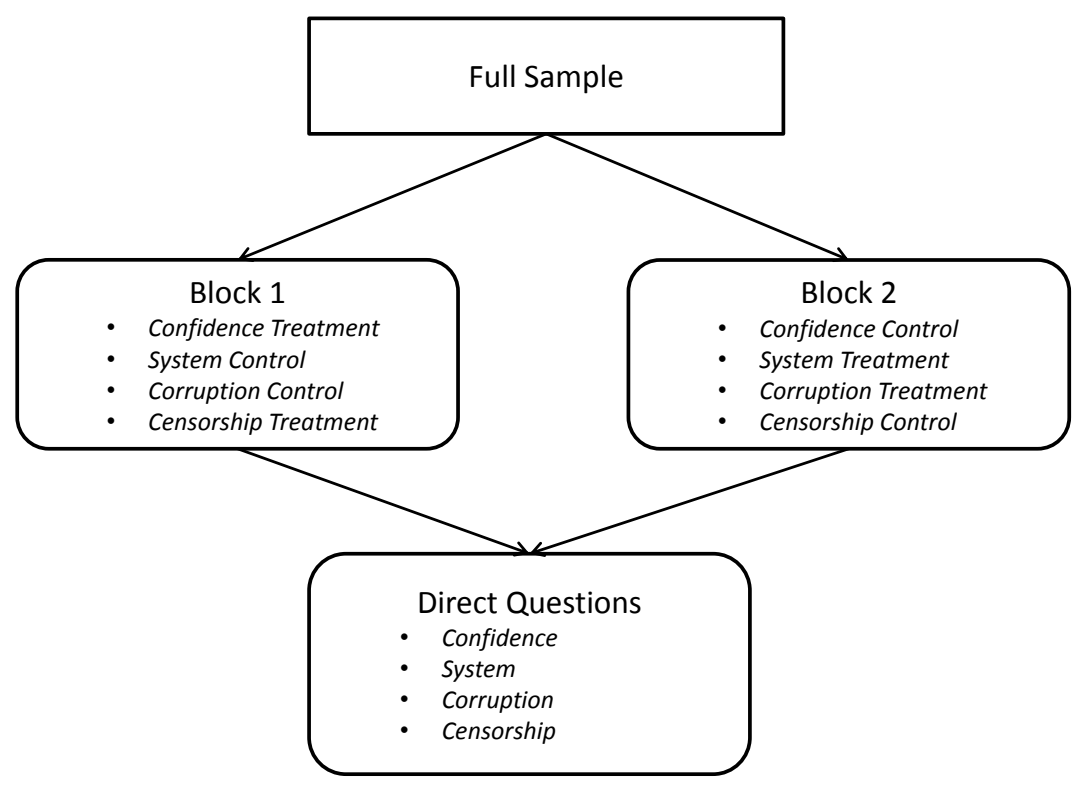

An alternative experimental design would have been to separate the sample into five groups, one control and four treatment groups - a separate group for each of our four sensitive items of interest. This set-up is known in the literature as the "multiple treatment" design (Blair and Imai, 2012). However, to maximize statistical power, we chose to present all four lists to all respondents thereby treating each list as an independent experiment of the "standard" design. Priming is mitigated by randomizing the order in which the lists are presented to respondents so our results cannot be said to be confounded by having received a particular treatment (control) list first.

All respondents were then asked the four sensitive items directly. Using Confidence as an example, they were asked, "Do you agree with the following statement, 'I have confidence in the national 
Table 3: Treatment and control lists by block

\begin{tabular}{l|l|l} 
& Block 1 & Block 2 \\
\hline Confidence & Treatment & Control \\
Corruption & Control & Treatment \\
System & Control & Treatment \\
Censorship & Treatment & Control
\end{tabular}

government." and presented with the options, "Yes", "No", or "Do not know". Responses to these questions are the basis for our estimates of support using the direct technique. The order of presentation of these four questions was also randomized, but all respondents received them immediately after responding to the list questions.

While it has been common in the application of list experiments to pose the direct question to a separate control group only (one which does not receive any list), or to ask of only the control-list group, asking the direct question of all respondents has two primary benefits. The first is that estimates of the direct item are made with greater precision, and the second is that information for all respondents is required for statistical analysis of the underlying assumptions behind the design (Blair and Imai, 2012; Aronow et al., 2015). The main risk with asking a treated individual a direct question in our application is potential priming effects. These are easy to diagnose; if being presented the treatment list primes one to respond a certain way to the direct question, treatment status should correlate with outcome of the direct question. We find however no evidence to suggest that this is the case for any of our four sensitive items (see Appendix B). Priming not being an issue, we retain our full sample in the analysis of all direct items.

\subsection{Estimation}

Estimates of regime support using the indirect questioning method are made by calculating a simple difference-in-means between the treatment and control groups. As respondents state the number of items from a list with which they agree, the overall mean values of the control and treatment groups for a specific item can theoretically differ by a maximum of 1 as this is the difference in the number of items with which they are presented. As such, the difference in means between the two groups is the best estimate of the proportion of individuals in the treatment group that answered affirmatively to the extra item, the treatment statement ${ }^{8}$. To determine the extent of self-censorship, we compare this estimate with those from the direct questioning method. Any statistically significant difference between the two point estimates is evidence of self-censorship as we assume that responses to indirect questioning are more representative of truthful preferences than are responses to direct measures.

For all direct questions respondents were given the options "Agree", "Do not agree", or "Do not know/Do not wish to say". We code all that agree as 1 and the two alternative responses as 0. Our estimates are therefore the proportion of all respondents that agree with the given statement. This

\footnotetext{
${ }^{8}$ Appendix Table A provides the full distribution of responses for each of the experiments.
} 
provides more conservative estimates of self-censorship than if we were to have excluded "Do not know" answers, but it is more consistent with the wording of the list experiments and subsequently more appropriate for comparison.

Table 4: Summary Statistics

\begin{tabular}{lcccccccc}
\hline & $\mathrm{n}$ & mean & $\mathrm{sd}$ & min & max & range & DKs & DK \% \\
\hline Gender & 1953 & 1.5 & 0.5 & 1.0 & 2.0 & 1.0 & 8 & 0.4 \\
Education & 1953 & 5.5 & 0.9 & 3.0 & 7.0 & 4.0 & 0 & 0.0 \\
Income & 1953 & 2.5 & 0.8 & 1.0 & 4.0 & 3.0 & 124 & 6.3 \\
YearBirth & 1953 & 1983.4 & 8.4 & 1939.0 & 2000.0 & 61.0 & 6 & 0.3 \\
Ethnicity & 1953 & 1.2 & 0.9 & 1.0 & 8.0 & 7.0 & 3 & 0.2 \\
Hukou & 1953 & 1.1 & 0.3 & 1.0 & 2.0 & 1.0 & 5 & 0.3 \\
Children & 1953 & 1.8 & 0.6 & 1.0 & 5.0 & 4.0 & 23 & 1.2 \\
PartyMember & 1953 & 1.7 & 0.5 & 1.0 & 2.0 & 1.0 & 24 & 1.2 \\
SourceInformation & 1953 & 3.7 & 0.8 & 1.0 & 5.0 & 4.0 & 0 & 0.0 \\
FatherEducation & 1953 & 4.2 & 1.3 & 1.0 & 8.0 & 7.0 & 0 & 0.0 \\
FatherParty & 1953 & 1.7 & 0.5 & 1.0 & 3.0 & 2.0 & 21 & 1.1 \\
MotherEducation & 1953 & 3.8 & 1.3 & 1.0 & 8.0 & 7.0 & 12 & 0.6 \\
MotherParty & 1953 & 1.9 & 0.4 & 1.0 & 3.0 & 2.0 & 6 & 0.3 \\
ConfidenceDirect & 1953 & 0.9 & 0.3 & 0.0 & 1.0 & 1.0 & 125 & 6.4 \\
SystemDirect & 1953 & 0.7 & 0.5 & 0.0 & 1.0 & 1.0 & 259 & 13.3 \\
CorruptionDirect & 1953 & 0.9 & 0.3 & 0.0 & 1.0 & 1.0 & 98 & 5.0 \\
CensorDirect & 1953 & 0.7 & 0.5 & 0.0 & 1.0 & 1.0 & 139 & 7.1 \\
ConfidenceTreat & 948 & 3.9 & 1.1 & 1.0 & 6.0 & 5.0 & 1 & 0.1 \\
SystemTreat & 1005 & 3.6 & 1.1 & 1.0 & 6.0 & 5.0 & 4 & 0.4 \\
CorruptionTreat & 1005 & 3.7 & 0.9 & 1.0 & 6.0 & 5.0 & 2 & 0.2 \\
CensorTreat & 948 & 3.4 & 1.0 & 1.0 & 6.0 & 5.0 & 0 & 0.0 \\
\hline
\end{tabular}

\section{Results}

The difference-in-means calculations are presented in Table 5 - Column 1 identifies the statement of interest, Column 2 is the proportion in agreement with the direct questioning method, Column 3 reports the proportion in agreement with the indirect questioning method, and Column 4 is the difference in the two proportions. A quick glance at the fourth column makes it readily apparent that falsification is present in all four of our survey items; direct questioning is a biased method of estimating regime support in China.

Considering confidence in the central government first, for the direct measure, $85.2 \%$ of respondents reported that they agreed with the statement, "I have confidence in the national government". This figure is consistent with the World Values Survey - 84.6\% of Chinese respondents in the 20102014 wave having reported confidence in the national government - but much less than the $94 \%$ that reported "trust" in the national government in the 2011 wave of the Asian Barometer. In contrast, 
according to the indirect method when the same statement was provided in a list, only $66 \%$ of individuals reported agreement; a difference of $19 \%$ which is statistically significant. Based on a $95 \%$ confidence interval, the estimated range of falsification is from $10 \%$ to $28 \%$ of respondents.

Table 5: Estimates of regime support: Direct and indirect questioning

\begin{tabular}{lccc}
\hline & Direct & Indirect & Difference \\
\hline Confidence & 0.852 & 0.659 & $-0.194^{* * *}$ \\
& $(0.008)$ & $(0.044)$ & $(0.047)$ \\
& $\mathrm{n}=1953$ & $\mathrm{n}=1948$ & \\
\hline Corruption & 0.849 & 0.629 & $-0.221^{* * *}$ \\
& $(0.008)$ & $(0.038)$ & $(0.04)$ \\
& $\mathrm{n}=1953$ & $\mathrm{n}=1951$ & \\
\hline System & 0.592 & 0.435 & $-0.157^{* * *}$ \\
& $(0.011)$ & $(0.045)$ & $(0.049)$ \\
& $\mathrm{n}=1953$ & $\mathrm{n}=1949$ & \\
\hline Censorship & 0.649 & 0.45 & $-0.199^{* * *}$ \\
& $(0.011)$ & $(0.044)$ & $(0.047)$ \\
& $\mathrm{n}=1953$ & $\mathrm{n}=1948$ & \\
\hline
\end{tabular}

Standard errors in parentheses

Moving on to the corruption measure, $85 \%$ of our respondents agree that the government is doing its best to root out corruption. $63.1 \%$ of respondents in the 2005-2008 Asian Barometer believed that the government was doing "something" or "its best" to crackdown on corruption, but this was estimated several years before Xi Jinping's anti-corruption campaign was started. We suspect that the introduction and high level of publicity that the campaign has received may be responsible for the diverging estimates. Being so closely associated with President Xi may have also increased the perceived sensitivity.

Again the point estimates from the indirect technique are substantially lower than the direct. Only an estimated $63 \%$ of respondents agree with the statement, a 22 percentage point difference. This estimate, along with all others, is statistically significant at the $99 \%$ confidence level indicating strong evidence of self-censorship. The range of falsification for this item based on $95 \%$ confidence intervals is $13 \%$ to $29 \%$ of respondents.

In calculating preference for the system of governance in China, $59.2 \%$ of respondents agreed with direct questioning that the current Chinese system was the better than any other they could think of $^{9}$. This is somewhat less than the $73.5 \%$ of the 2005-2008 Chinese Asian Barometer respondents agreed or strongly agreed that "Whatever its faults, our form of government is still the best for us", but not drastically so. The 2011 Wave posed the question in the following manner, "Compared to other systems in the world would you say our system of governance works fine as it is, needs minor change, needs major change, or should be replaced?", to which a similar $71.8 \%$ of respondents

\footnotetext{
${ }^{9}$ The non-response rate for this item was $13.1 \%$ which may account for some of this difference.
} 
believed that the system needed only minor change or works fine. For this measure as well we find evidence of substantial self-censorship when comparing direct and indirect estimates. Only $43.5 \%$ are estimated to believe that the Chinese system of governance is the best with indirect questioning, a difference of $15.7 \%$. The range of falsification for this item based on $95 \%$ confidence intervals is 5.7 to 25 percentage points.

For our final sensitive item, support for government censorship, we find that $65 \%$ of our sample states that they believe the government should have the right to prevent the media from publishing potentially destabilizing remarks. This is somewhat higher than in a representative sample collected in 2011; in Wave 3 of the Mainland China portion of the Asian Barometer, respondents were asked to state their preference of two statements, "The media should have the right to publish news and ideas without government control", and "the government should have the right to prevent the media from publishing things that may be politically destabilizing". Only $45 \%$ of respondents believed that the government should have the right to prevent the media from publishing potentially destabilizing remarks, however $13.3 \%$ chose a neutral response and a further $3.6 \%$ chose not to answer the question - a strong indication of sensitivity. Among those that did provide a response, $54 \%$ believe that censorship is acceptable which is much closer to the estimate from our sample.

We find a similar degree of self-censorship regarding government censorship as we do for the other sensitive items in our study. The indirect point estimate of $45 \%$ is a full 20 percentage points lower than the direct method estimate, and is again highly statistically significant. The range of falsification based at the $95 \%$ confidence interval is $11 \%$ to $29 \%$ of respondents.

To summarize, we find strong evidence of self-censorship for all four of our sensitive items, the extent of which ranges from 16 percentage points (System) to 22 percentage points (Corruption). These results are represented graphically as well in Figure 2. The sensitive statements in both direct and indirect form run along the $\mathrm{y}$-axis, and the proportion of respondents in agreement with the given technique from 0 to 1 along the $\mathrm{x}$-axis. Line type and shape discriminate between the four items; Confidence (dots with solid lines); Corruption (squares with long dashed lines); System (triangles with short dashed lines); Censorship (Xs with dashed lines). For each item and method the estimated proportion is shown with points, and the $95 \%$ confidence interval is represented by the corresponding vertical lines. The much larger confidence intervals that are reported in the indirect questions is a reflection of the comparative imprecision of the list experiment technique. Nevertheless, the differences are so large that there is no overlap in confidence intervals for any of the items.

\subsection{Who Falsifies?}

In order to determine individual characteristics which lead one to self-censor, we examine the difference between fitted values of the indirect and direct techniques by subgroup with the inclusion of demographic control variables. We examine income, education, age, gender, party membership, urban or rural hukou (household registration) status, and respondent's belief in who commissioned 
Figure 2: Point estimates with confidence intervals by item and technique

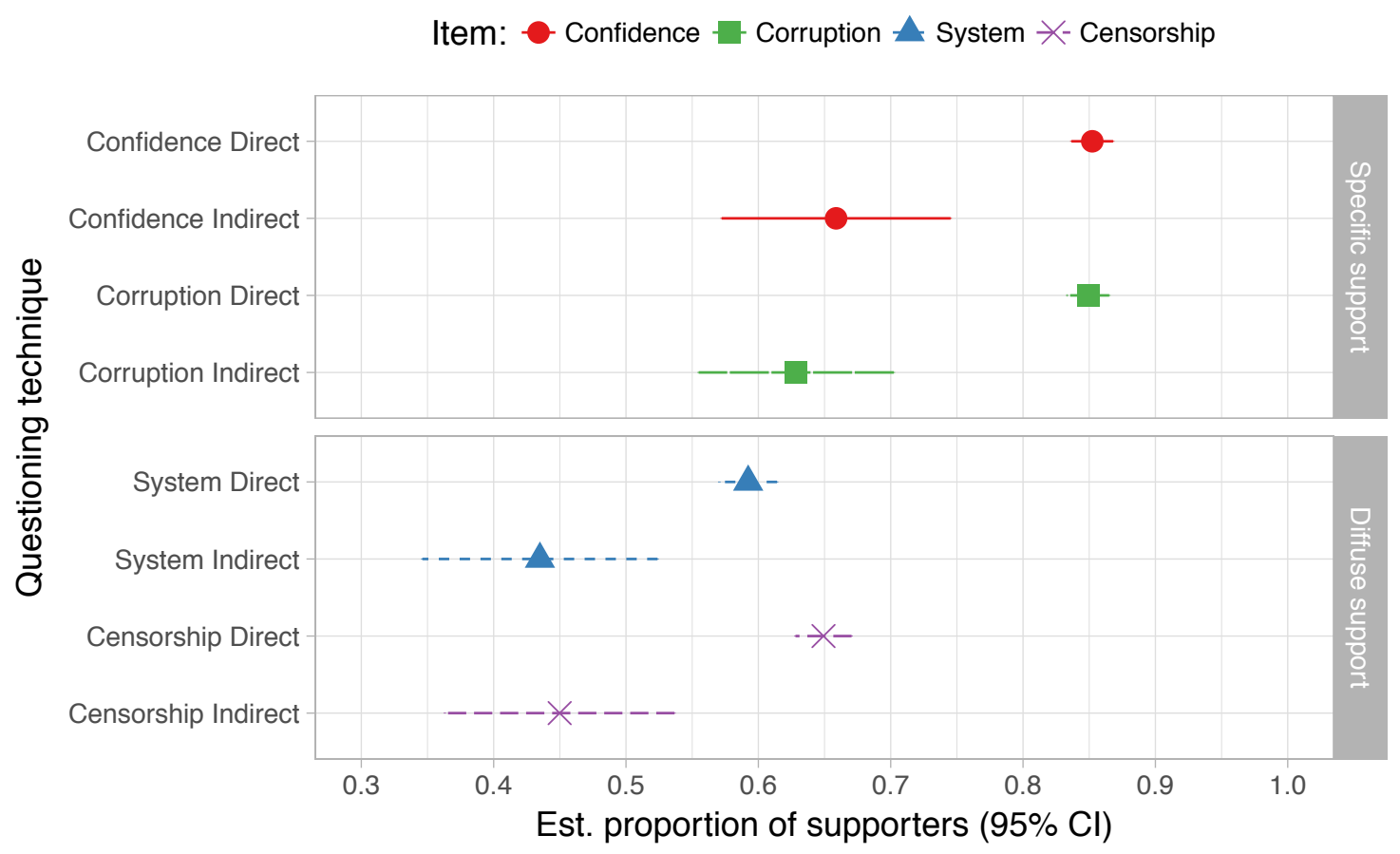

the survey (government or not). In each case we divide the sample into two subgroups based on the median value of the characteristic of interest. We then estimate fitted models of the likelihood of answering affirmatively to the list item while controlling for the remaining variables, and similarly fit a multiple regression model of the likelihood of answering affirmatively to the direct question item. For example, in the case of income, we create two subgroups - high and low income as defined by the median level of income - and estimate models while controlling for age, education, gender, party membership, urban or rural hukou, and government or non-government commission separately for each group. In the case of education, we create sub-samples based on the median level of education, and estimate separate models with controls for income, age, gender, party membership, urban or rural hukou, and government or non-government commission. We do this for all 7 variables of interest. Multiple regression estimates of the list items are conducted using the List package in $\mathrm{R}$ as outlined by Blair and Imai (2012). Estimates of the direct item are done with logistic regression. After fitting the models by subgroup, we then calculate the difference between estimated support by the indirect method and estimated support by the direct method of questioning. This difference is our measure of self-censorship by subgroup while controlling for the remaining variables. Any difference in the amount of self-censorship between the two subgroups is evidence that the characteristic that defined these two particular subgroups is relevant in determining self-censorship. 
We develop a priori hypotheses of our expectations of the characteristics that should lead one to self-censor and falsify their survey responses. Our guiding premise is the notion that preference falsification should be practiced to a greater degree by those that have more to lose (Kuran, 1997; Jiang and Yang, 2016). This leads us to predict that we should find greater falsification among the wealthy and the higher educated based on the fact that they have greater economic resources at stake. Further, we should expect those with urban hukou (household registration) status to falsify to a greater extent than rural hukou because of the design of the Chinese social system. Specifically, all state-funded social services such as education and health care are available to citizens in the locality of their hukou only. Therefore, if one is registered in a different locality from where one currently resides, they must travel to their hukou locality in order to gain access to state-funded services, or pay for private services in the locality in which they reside. This system further creates an urban/rural divide as the extent of public services in cities is far greater than in rural regions; those that live in cities have access to government services that are simply unavailable to rural residents. This includes better schools for children and access to health care facilities not available in poor and sparsely populated areas. As a result, we predict urban residents should show a greater likelihood to self-censor.

A similar logic can be applied to party members. Beyond access to the political apparatus, members also have access to economic benefits such as jobs. As such, one should expect greater falsification among party members. However, it is possible that those that seek membership in the party are to a greater extent than non-members believers in the system. Less self-censorship among members may be the result of high levels of support in both the direct and indirect methods of investigation.

With respect to age our premise of resource loss does not directly apply with control for other background factors. We would nevertheless expect older respondents to falsify more because of their lived experience of more repressive periods of $\mathrm{CCP}$ rule such as the cultural revolution and Tiananmen square protests (see eg Jiang and Yang, 2016). However given the relatively young sample that a web-based survey produces it is not clear that there is sufficient variability in age for this relationship should materialize.

We expect to find gender based differences in falsification such that women should self-censor to a greater extent than men. Risk-aversion theory argues that women are in general more risk averse than men (Eckel and Grossman, 2008), and should as a result be more likely to avoid the unnecessary risk of criticizing the regime in an academic survey. Further, as in many countries there are gendered differences in economic and labour market outcomes in China. As systemic forms of discrimination imply that women typically need to work harder than men in order to gain the same economic standing, one may expect them to be more cautious of that standing in line with our resource loss premise.

Lastly, in relation to who one believes to have commissioned the survey, we would expect that those that believe the government commissioned the survey to falsify more. Note that we specifically 
informed respondents before beginning the survey that the work was being conducted on behalf of an independent, foreign university. Holders of this belief may be inherently untrusting of the government and therefore less likely to take the risk of expressing disapproval. On the other hand, individuals that believe that the government is responsible for the survey may falsify to a lesser extent if they consider such government-sponsored questioning as a signal that the expression of such beliefs is pre-approved. That is, one may believe that if one was not allowed to express lack of support for the government, the government would not provide one with the opportunity to do so. This line of reasoning would also help to explain the results found in Lei and $\mathrm{Lu}$ (2017) that respondents are more critical of the government when the enumerator is a CCP member rather than a university researcher. Those that believe that an independent research institution was responsible for the survey may rather choose to "play it safe" and over-report their support due to an inherent uncertainty over where the threshold of sensitivity truly lies, which would result in greater falsification among this group.

Figure 3 reports the estimated difference between these two questioning techniques by subgroup for the all of the four items: confidence in the national government; belief in the sincerity of an ongoing anti-corruption campaign; preference for the existing system of government; and support for government censorship. ${ }^{10}$ The points represent estimated proportions and the horizontal bars the $95 \%$ confidence intervals. At a glance, most subgroups appear to practice self-censorship to a similar extent with regards to all four items, but there are exceptions.

Age defines the first two subgroups (born before 1985 - our sample median - or after), and here we see that there is tendency among younger respondents to self-censor to a higher degree than do older respondents. The pattern appears for three out of the four items, although the differences between the groups are not statistically significant. This is contrary to our expectation but again, the relatively young sample that we have may explain this divergence between observation and expectation. An possible alternative hypothesis is that younger respondents have more knowledge of the state's online reach, causing them to self-censor to a larger extent than older respondents, who may feel more secure about their anonymity online.

Party membership, the second subgroup, is distinctly irrelevant in determining falsification. This result is somewhat surprising as we may have expected a difference between the two groups, but when controlling for other characteristics this is not the case. This may be due to the fact that the party actively recruits the wealthy and highly educated (Dickson, 2007) such that falsification may be the result of these factors rather than party membership per se. Indeed, when controls are excluded from the estimates of support for censorship up to $26 \%$ of party members falsify whereas only $18 \%$ falsify among non members. Further, party members are significantly more likely than non members to support censorship in direct questioning stating on average $6 \%$ greater likelihood of explicit support. While this is not a vast difference between the two groups, it does nevertheless indicate that party members hold more regime sympathetic views than do non members among

\footnotetext{
${ }^{10}$ For reference Appendix 4 plots subgroup differences for estimates from the direct questions.
} 
Figure 3: Self-censorship by subgroup for each list item

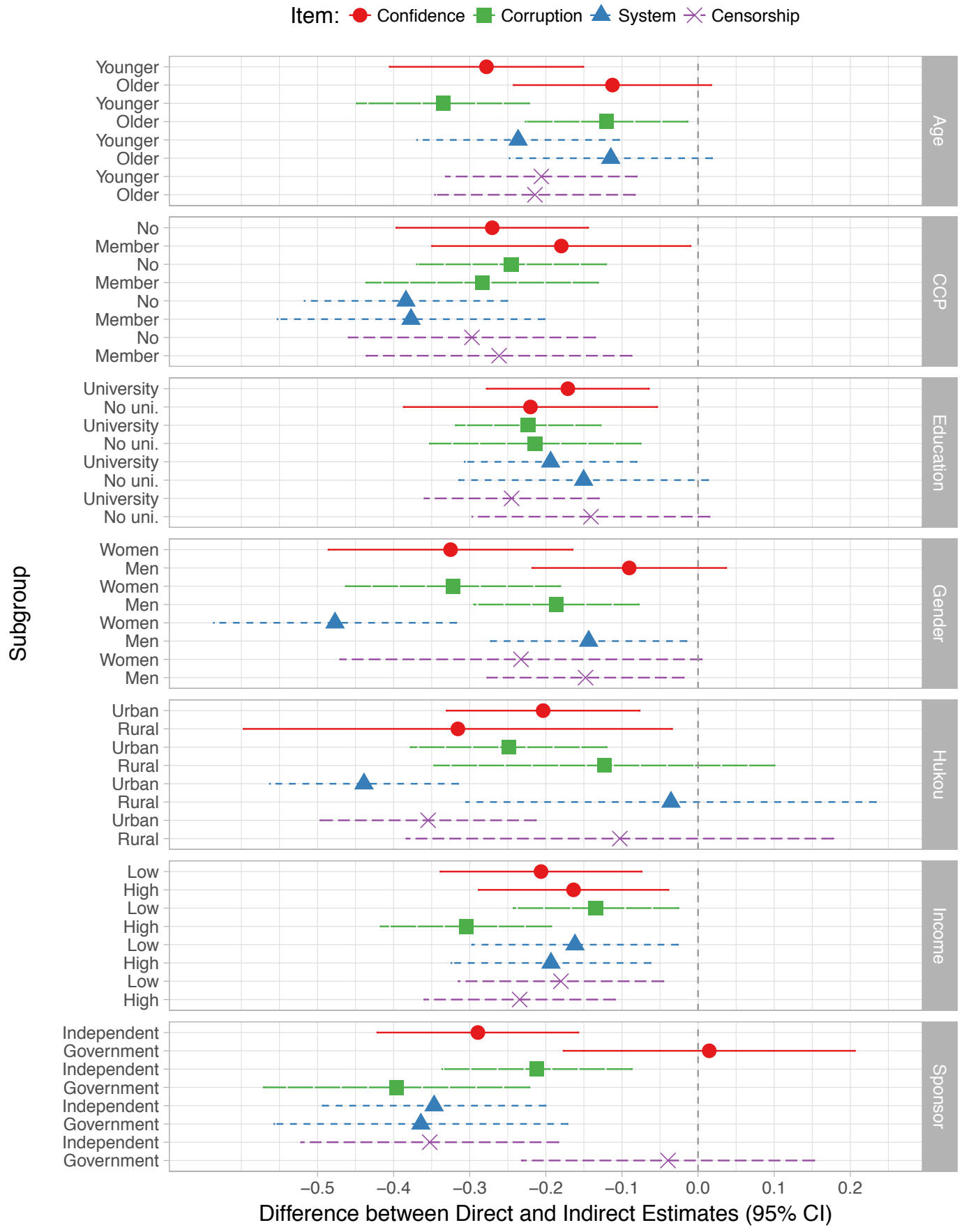


our sample when controlling for other factors such as income, education, gender, and hukou status. While personal benefits such as access to jobs undoubtedly factor in for some in the decision to join the party, political support nevertheless remains as a significant factor.

Education is not relevant in determining self-censorship in China for all items, but it is in relation to support for government censorship, the dashed lines with Xs. Given that we have a web-sample we do not find substantial variation in education. As such, we have defined our subgroups as those that studied at the Bachelor's level or above and those that studied junior college or below. With regards to censorship, the higher and lower educated are predicted to have the same levels of support in direct questioning, the difference observed here between levels of falsification is rather the result of lower true levels of support for censorship among the university educated than among those that studied to the junior college level or lower. With direct questioning $66 \%$ of the lower educated and $65 \%$ of the higher educated are predicted to support censorship. However, a large difference appears when estimates are made with our indirect list experiment. In this case, while $53 \%$ of the lower educated are predicted to support censorship, only $40 \%$ of the higher educated do so. The difference between the direct and indirect methods for the university educated is nearly twice as large as that of the lower educated (-0.25 and -0.14 respectively) which suggests that education is relevant in determining preference falsification of censorship, even among our highly educated sample. This is consistent with prior work (see Jiang and Yang, 2016), but it is unclear if this is a linear relationship or if university education is decisive.

Gender also appears to be a factor in determining the level of self-censorship, with women showing a greater propensity to falsify their responses. Each of the four items show this tendency, albeit it is only the estimates for preference for the existing system of government, short dashed line with triangles, for which confidence intervals show no overlap. These results confirm our prior expectation that women should falsify more than men.

Those with urban hukou (household registration) are more likely to falsify their preferences than are those with rural hukou, similarly supporting our prior expectation. This is true for three out of the four lists. Moreover this difference is substantial with a difference in the propensity to self-censor of 31 percentage points with regards to preference for the existing system of government, dashed line with triangles, and 25 percentage points, for support for government censorship, dashed line with Xs. This result is consistent with Li (2004) who found that rural residents are willing to openly criticize the regime. However, the sharp difference we find between rural and urban residents calls into question the validity of the assumption that many researchers have subsequently made based on this finding - that open criticism of the regime among rural residents is indicative of a lack of self-censorship generally in China. Urban residents are, according to our estimates, the most likely of any sub-group to self-censor. Predicted values from our multiple regression models show that a large majority, a full $78 \%$ of respondents, state that they support censorship in direct questioning, whereas only $43 \%$ are estimated to support the practice if asked indirectly. The difference between rural and urban residents arises through differences in the level of support with indirect questioning 
- that is, true preferences. A similar proportion of rural to urban residents support censorship with direct questioning, $75 \%$ and $78 \%$ respectively, but with $64 \%$ of rural residents stating support with the indirect question compared to $43 \%$ of urban residents, it can be concluded that a substantially larger portion of rural residents support authoritarian rule than do urban residents.

Income level defines the next two subgroups, and as predicted we see that there is some difference between high and low income earners, yet neither difference is significant. With direct questioning $87 \%$ of high income earners state that they that believe Xi's anti-corruption campaign is a sincere effort to root out corruption whereas $83 \%$ of low income earners share this sentiment. However, this difference is the manifestation of self-censorship by the wealthy rather than true differences in belief. Using indirect questioning the level of belief in the campaign is substantially smaller for both groups, and in fact smaller among the high-income earners.

Lastly, respondents that believe that the government commissioned the survey appear to be less likely to falsify with regards to two of the four items than are those that believe that an independent research institute (or other organization) commissioned the survey. For confidence in the national government, long-dashed line with squares, the relationship is reversed, and with regards to preference for the existing system of government, dashed lines with triangles, belief about survey sponsor is distinctly irrelevant in determining self-censorship. These results are therefore consistent with our "signal" hypothesis in that individuals may believe that if the government gives the option to disapprove it is not a risk to do so. These results are consistent with Lei and Lu (2017)'s findings, but they also show that their finding that individuals are more critical of the government to a CCP enumerator cannot be viewed as evidence that self-censorship on surveys does not exist.

\section{Conclusion}

The study of authoritarian regimes has long used survey data to determine the extent, causes, and consequences of popular support for non-democratic rule. Implicit in this approach has been the assumption that respondents are willing to express their true opinions with respect to political topics. In order to test this assumption we apply a technique often used to overcome social desirability bias, the list experiment, to the study of self-censorship in China.

We study self-censorship in relation to four politically sensitive survey items: confidence in the national government; belief in the sincerity of an ongoing anti-corruption campaign; preference for the existing system of government; and support for government censorship. We find that selfcensorship is present and substantial for all four of our sensitive items; $16-22 \%$ of respondents that state regime support in direct questioning in fact hold regime-critical opinions. In spite of the presence of extensive self-censorship, this study nevertheless finds that the Chinese regime does in fact enjoy popular support in relation to the current leadership - that is, the regime enjoys specific support. A majority of respondents express confidence in the national government and believe that the current anti-corruption campaign - a flagship policy of the President Xi - is a sincere 
attempt to root out graft. A large proportion of respondents are less than forthcoming in direct questioning which exposes these measures of regime support to self-censorship as well. But estimates with indirect questioning nevertheless show that a substantial majority, $66 \%$ and $63 \%$ respectively, support the regime with these measures.

Estimates of diffuse support for more long-standing, system-level institutions of CCP rule are however substantially less flattering to the regime. While direct questioning shows that a majority of respondents support the regime even with these measures, indirect questioning shows that true levels of support are much lower. In particular, we ask if respondents agree that their system of government is "better than any other I can think of" and that the government "should have the right to prevent the media from publishing things that might be politically destabilizing". $60 \%$ and $65 \%$ of respondents agree with these two statements when asked directly, but only $44 \%$ and $45 \%$ do so when asked indirectly. While support for the current leadership may help to offset any potential negative consequences of such low institutional support in the short term, any eventual failure on the part of leadership may present problems for the regime given that it is lacking support for more enduring features of its rule.

We also investigate the individual-level characteristics associated with self-censorship and show that falsification of survey responses is most prevalent among the wealthy, younger, female, and urban respondents of our sample. Falsification among these subgroups however occurs in two different manners. The wealthy do not differ from the less-wealthy in their true beliefs, but they do claim to support the regime more with direct questioning. Urban residents on the other hand hold substantially less favorable regime friendly views with indirect questioning than do rural respondents, which indicates that this factor is related to anti-authoritarian attitudes. However, increased self-censorship among the urbanites in direct questioning gives the appearance that hukou status is not a significant factor in determining regime support in China.

Lastly, using direct measures women differ only marginally from men, but are considerably more critical of the regime than men when measured with indirect techniques. Women do falsify more than men, which may be the result of the fact that true support is so low that it affords greater opportunity to falsify. Alternatively, like in most countries, women in China suffer from asymmetrical labor market outcomes and gender-based wage penalties. As such it may be the case that they are more likely than men to self-censor because they face more obstruction in obtaining favorable social and economic positions and are therefore more risk averse to losing such status.

We argue that our sample, though not representative of the wider population, does allow for generalization to China's online population and in particular, netizens. Even in the potential absence of self-censorship among the population as a whole, the results here are nevertheless relevant to the literature which studies the individual-level factors related to regime support. We find that falsification is most prevalent among the wealthy, the young, urban, and female respondents, which means that cross-sectional studies of the individual characteristics of regime support in authoritarian regimes are likely invalidated by this systematic bias in response sincerity. 
This study provides a significant contribution to the literature in two respects. First, it contributes to a nascent literature which has begun to differentiate between expressed and true opinions in authoritarian regimes. In terms of political attitudes these are often thought to be one and the same which is often - but not always - the case in democracies. However, this literature has begun to demonstrate that this assumption does not hold in nondemocratic contexts. Related, the more direct contribution of this study is to raise the issue that survey research in China and other authoritarian regimes may be more subject to self-censorship than was previously thought. As such, results from previous research that claim extraordinarily high popular support for the Chinese regime must be re-considered if results from this study are to be replicated on a larger scale.

Given that this study is, to the best of our knowledge, the first to estimate the extent of selfcensorship in an authoritarian regime of these measures of institutional and current leadership support, the results here necessitate further study of these and theoretically related survey items. This is particularly prudent given the extensive use of such items in cross-national research due to their presence in international survey projects such as the World Values Survey and the various Barometer studies. Further, research needs to be done to replicate these findings both with a wider sample in China and other contexts, with different measures of political attitudes, and with different survey techniques, which will give us a better understanding of the extent of the problem and how to overcome it. 


\section{References}

Aronow, Peter M, Alexander Coppock, Forrest W Crawford and Donald P Green. 2015. "Combining list experiment and direct question estimates of sensitive behavior prevalence." Journal of Survey Statistics and Methodology p. smu023.

AsianBarometer. 2008. "Asian Barometer Survey Data Release: 2001-2003, 2005-2008." URL: http://www. asianbarometer. org .

Blair, Graeme and Kosuke Imai. 2012. "Statistical analysis of list experiments." Political Analysis pp. $47-77$.

Buhrmester, Michael, Tracy Kwang and Samuel D Gosling. 2011. "Amazon's Mechanical Turk a new source of inexpensive, yet high-quality, data?" Perspectives on psychological science 6(1):3-5.

Chen, Xueyi and Tianjian Shi. 2001. "Media effects on political confidence and trust in the People's Republic of China in the post-Tiananmen period." East Asia 19(3):84-118.

China Daily, CD. 2017. "TV drama highlights real-life graft cases." China Daily .

Chu, Yun-han, Larry Diamond, Andrew J Nathan and Doh Chull Shin. 2008. How East Asians View Democracy. Columbia University Press.

Chung, Janne and Gary S Monroe. 2003. "Exploring social desirability bias." Journal of Business Ethics 44(4):291-302.

Corstange, Daniel. 2009. "Sensitive questions, truthful answers? Modeling the list experiment with LISTIT." Political Analysis pp. 45-63.

Dickson, BJ. 2007. "Integrating Wealth and Power in China: The Communist Party's Embrace of the Private Sector." The China Quarterly 192(December):827-854.

Dickson, Bruce. 2016. The Dictator's Dilemma: The Chinese Communist Party's Strategy for Survival. Oxford University Press.

Dickson, Bruce J, Pierre F Landry, Mingming Shen and Jie Yan. 2016. "Public Goods and Regime Support in Urban China." The China Quarterly 228:859.

Easton, David. 1965. A framework for political analysis. Vol. 25 Prentice-Hall Englewood Cliffs, NJ.

Eckel, Catherine C and Philip J Grossman. 2008. "Men, women and risk aversion: Experimental evidence." Handbook of experimental economics results 1:1061-1073.

Frye, Timothy, Scott Gehlbach, Kyle L Marquardt and Ora John Reuter. 2017. "Is Putins popularity real?" Post-Soviet Affairs 33(1):1-15. 
Geddes, Barbara and John Zaller. 1989. "Sources of popular support for authoritarian regimes." American Journal of Political Science pp. 319-347.

Gingerich, Daniel W, Virginia Oliveros, Ana Corbacho and Mauricio Ruiz-Vega. 2016. "Corruption as a self-fulfilling prophecy: evidence from a survey experiment in Costa Rica." American Journal of Political Science 60(4).

Glynn, Adam N. 2013. "What can we learn with statistical truth serum? Design and analysis of the list experiment." Public Opinion Quarterly 77(S1):159-172.

Gonzalez-Ocantos, Ezequiel, Chad Kiewiet De Jonge, Carlos Meléndez, Javier Osorio and David W Nickerson. 2012. "Vote buying and social desirability bias: Experimental evidence from Nicaragua." American Journal of Political Science 56(1):202-217.

Heerwegh, Dirk. 2009. "Mode differences between face-to-face and web surveys: an experimental investigation of data quality and social desirability effects." International Journal of Public Opinion Research 21(1):111-121.

Holbig, Heike and Bruce Gilley. 2010. "Reclaiming legitimacy in China." Politics and policy $38(3): 395-422$.

Holbrook, Allyson L and Jon A Krosnick. 2010. "Social desirability bias in voter turnout reports tests using the item count technique." Public Opinion Quarterly 74(1):37-67.

Huang, Haifeng and Yao-Yuan Yeh. 2017. "Information from Abroad: Foreign Media, Selective Exposure and Political Support in China." British Journal of Political Science pp. 1-26.

Imai, Kosuke. 2011. "Multivariate regression analysis for the item count technique." Journal of the American Statistical Association 106(494):407-416.

International, Amnesty. 2016. Amnesty International Report 2016/17: The state of the world's human rights. Technical report Amnesty International.

Jiang, Junyan and Dali L Yang. 2016. "Lying or Believing? Measuring Preference Falsification From a Political Purge in China." Comparative Political Studies 49(5):600-634.

Kalinin, Kirill. 2016. "The social desirability bias in autocrat's electoral ratings: evidence from the 2012 Russian presidential elections." Journal of Elections, Public Opinion and Parties 26(2):191211.

Kennedy, John James. 2009. "Maintaining Popular Support for the Chinese Communist Party: The Influence of Education and the State-Controlled Media." Political Studies 57(3):517-536.

King, Gary, Jennifer Pan and Margaret E Roberts. 2013. "How censorship in China allows government criticism but silences collective expression." American Political Science Review 107(02):326343. 
Krumpal, Ivar. 2013. "Determinants of social desirability bias in sensitive surveys: a literature review." Quality \& Quantity 47(4):2025-2047.

Kuklinski, James H, Michael D Cobb and Martin Gilens. 1997. "Racial attitudes and the New South." The Journal of Politics 59(02):323-349.

Kuran, Timur. 1997. Private truths, public lies: The social consequences of preference falsification. Harvard University Press.

Lam, Willy. 2015. "Growing CCDI Power Brings Questions of Politically-Motivated Purge." China Brief 15(3):7-9.

Lei, Xuchuan and Jie Lu. 2017. "Revisiting Political Wariness in Chinas Public Opinion Surveys: Experimental Evidence on Responses to Politically Sensitive Questions." Journal of Contemporary China 26(104):213-232.

Lei, Ya-Wen. 2011. "The political consequences of the rise of the Internet: Political beliefs and practices of Chinese netizens." Political Communication 28(3):291-322.

Li, Lianjiang. 2004. "Political trust in rural China." Modern China 30(2):228-258.

Lu, Xiaobo. 2016. Ethical Challenges in Comparative Politics Experiments in China. In Ethics and Experiments: Problems and Solutions for Social Scientists and Policy Professionals, ed. Scott Desposato. London: Routledge.

MacKinnon, David, P. 2008. Introduction to statistical mediation analysis. New York, London: Routledge Academic.

Manion, Melanie. 2016. "Taking Chinas anticorruption campaign seriously." Economic and Political Studies 4(1):3-18.

Miller, Blake and Mary Gallagher. 2018. "The Progression of Repression: When does online censorship move toward real world repression?".

URL: http://www.blakeapm.com/research/repression

Nathan, Andrew J. 2007. "Political culture and diffuse regime support in Asia." Asian-Barometer Working Paper Series, no. 43).

Qin, Bei, David Strömberg and Yanhui Wu. 2017. "Why Does China Allow Freer Social Media? Protests versus Surveillance and Propaganda." The Journal of Economic Perspectives 31(1):117140.

Saich, Tony. 2014. Reflections on a Survey of Global Perceptions of International Leaders and World Powers. Technical report. 
Schedler, Andreas. 1999. The self-restraining state: power and accountability in new democracies. Lynne Rienner Publishers.

Shi, Tianjian. 2001. "Cultural values and political trust: a comparison of the People's Republic of China and Taiwan." Comparative Politics pp. 401-419.

Shi, Tianjian. 2008. Democratic values supporting an authoritarian system. In How East Asians View Democracy, ed. Yun-han Chu, Larry Diamond, Andrew J Nathan and Doh Chull Shin. Columbia University Press.

Stockmann, Daniela, Ashley Esarey and Jie Zhang. 2017. "Who Is Afraid of the Chinese State? Evidence Calling into Question Political Fear as an Explanation for Overreporting of Political Trust." Political Psychology .

Stockmann, Daniela and Mary E Gallagher. 2011. "Remote control: How the media sustain authoritarian rule in China." Comparative Political Studies p. 0010414010394773.

Tannenberg, Marcus. 2017. "The Autocratic Trust Bias: Politically Sensitive Survey Items and Selfcensorship." University of Gothenburg, Varieties of Democracy Institute: Working Paper (49).

Tourangeau, Roger and Ting Yan. 2007. "Sensitive questions in surveys." Psychological bulletin $133(5): 859$.

Truex, Rory. 2014. "Consultative authoritarianism and its limits." Comparative political studies p. 0010414014534196.

UNDP. 2016. Report on Sustainable Financing for Poverty Alleviation in China. Technical report United Nations Development Program.

Wang, Zhengxu. 2005. "Political trust in China: Forms and causes." Legitimacy: ambiguities of political success or failure in East and Southeast Asia pp. 126-38.

Wang, Zhengxu. 2006. "Explaining regime strength in China." China: An International Journal $4(02): 217-237$.

Wedeman, Andrew. 2017. "Xi Jinping's Tiger Hunt: Anti-corruption Campaign or Factional Purge?" Modern China Studies 24(2):35.

Weghorst, Keith. 2011. "Political attitudes and response bias in semi-democratic regimes: A survey experiment comparing the list experiment and randomized response in Tanzania." Working article 


\section{A Frequency distributions}

Table 6: Frequency distributions of responses for each the experiments

\begin{tabular}{c|c|c|c|c|c|c|c|c}
\hline$\#$ & \multicolumn{2}{|c}{ Confidence } & \multicolumn{2}{c}{ System } & \multicolumn{2}{c}{ Corruption } & \multicolumn{2}{c}{ Censorship } \\
\hline & Control & Treatment & Control & Treatment & Control & Treatment & Control & Treatment \\
\hline $\mathbf{0}$ & 17 & 8 & 19 & 20 & 8 & 11 & 44 & 22 \\
$\mathbf{1}$ & 150 & 83 & 194 & 132 & 158 & 81 & 248 & 151 \\
$\mathbf{2}$ & 489 & 241 & 408 & 331 & 520 & 256 & 415 & 323 \\
$\mathbf{3}$ & 268 & 340 & 268 & 313 & 238 & 477 & 260 & 311 \\
$\mathbf{4}$ & 77 & 217 & 59 & 158 & 24 & 159 & 33 & 122 \\
$\mathbf{5}$ & N/A & 58 & N/A & 47 & N/A & 19 & N/A & 19 \\
\hline
\end{tabular}

Table 7: Proportion of responses for each the experiments

\begin{tabular}{c|c|c|c|c|c|c|c|c}
\hline$\#$ & \multicolumn{2}{|c}{ Confidence } & \multicolumn{2}{c}{ System } & \multicolumn{2}{c}{ Corruption } & \multicolumn{2}{c}{ Censorship } \\
\hline & Control & Treatment & Control & Treatment & Control & Treatment & Control & Treatment \\
\hline $\mathbf{0}$ & 0.02 & 0.008 & 0.02 & 0.02 & 0.008 & 0.01 & 0.04 & 0.02 \\
$\mathbf{1}$ & 0.15 & 0.09 & 0.2 & 0.13 & 0.17 & 0.08 & 0.25 & 0.16 \\
$\mathbf{2}$ & 0.49 & 0.25 & 0.43 & 0.33 & 0.55 & 0.26 & 0.42 & 0.34 \\
$\mathbf{3}$ & 0.27 & 0.36 & 0.28 & 0.31 & 0.25 & 0.48 & 0.26 & 0.33 \\
$\mathbf{4}$ & 0.08 & 0.23 & 0.06 & 0.15 & 0.03 & 0.16 & 0.03 & 0.13 \\
$\mathbf{5}$ & N/A & 0.06 & N/A & 0.047 & N/A & 0.019 & N/A & 0.02 \\
\hline
\end{tabular}




\section{B Priming Effect Estimates}

Table 8: Effect of Treatment Status (Group) on Direct Question

\begin{tabular}{lcccc}
\hline & Model 1 & Model 2 & Model 3 & Model 4 \\
\hline (Intercept) & $1.80^{* * *}$ & $0.40^{* *}$ & $1.84^{* * *}$ & $0.83^{* * *}$ \\
& $(0.20)$ & $(0.15)$ & $(0.20)$ & $(0.15)$ \\
Group & -0.03 & -0.02 & -0.07 & -0.14 \\
& $(0.13)$ & $(0.09)$ & $(0.13)$ & $(0.10)$ \\
\hline AIC & 1636.81 & 2640.39 & 1657.42 & 2528.63 \\
BIC & 1647.96 & 2651.54 & 1668.57 & 2539.79 \\
Log Likelihood & -816.40 & -1318.19 & -826.71 & -1262.32 \\
Deviance & 1632.81 & 2636.39 & 1653.42 & 2524.63 \\
Num. obs. & 1950 & 1950 & 1950 & 1950 \\
\hline${ }^{* * *} p<0.001,{ }^{* *} p<0.01,{ }^{*} p<0.05$ & & &
\end{tabular}




\section{Balance Table}

Table 9: Balance Table - Mean Values by Block

\begin{tabular}{lcc}
\hline & Block 1 & Block 2 \\
\hline Gender & 1.51 & 1.49 \\
Education & 5.43 & 5.44 \\
Income & 2.52 & 2.55 \\
YearBirth & 1983.73 & 1983.18 \\
Ethnicity & 1.16 & 1.24 \\
Hukou & 1.12 & 1.10 \\
Children & 1.85 & 1.85 \\
PartyMember & 1.71 & 1.70 \\
SourceInformation & 3.72 & 3.62 \\
FatherEducation & 4.17 & 4.17 \\
FatherParty & 1.70 & 1.69 \\
MotherEducation & 3.76 & 3.77 \\
MotherParty & 1.85 & 1.86 \\
\hline
\end{tabular}




\section{Subgroup Analysis}

Figure 4: Support by Subgroup - Direct Technique

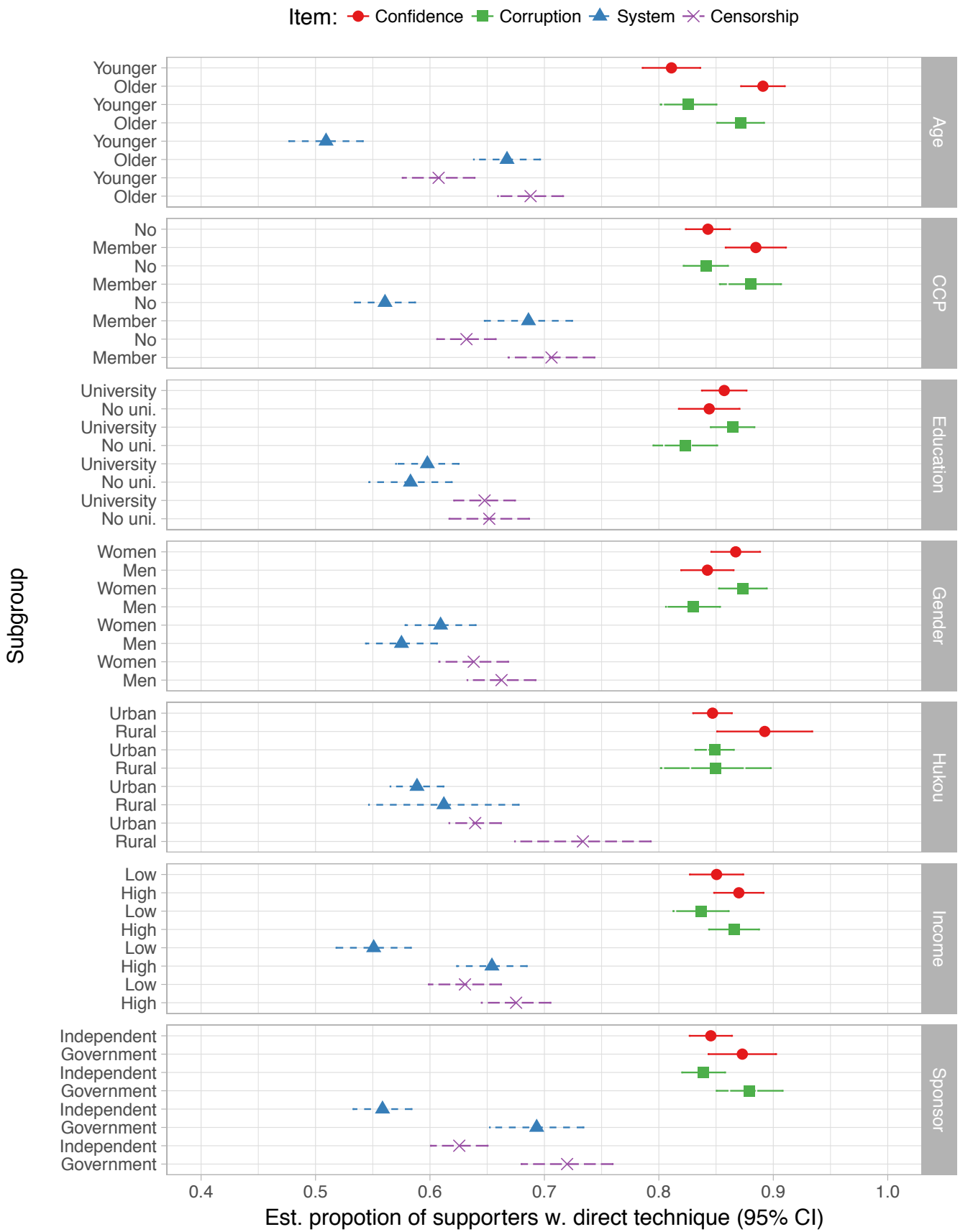




\section{E Geographical Distribution}

Figure 5: Geographical Distribution of Respondents

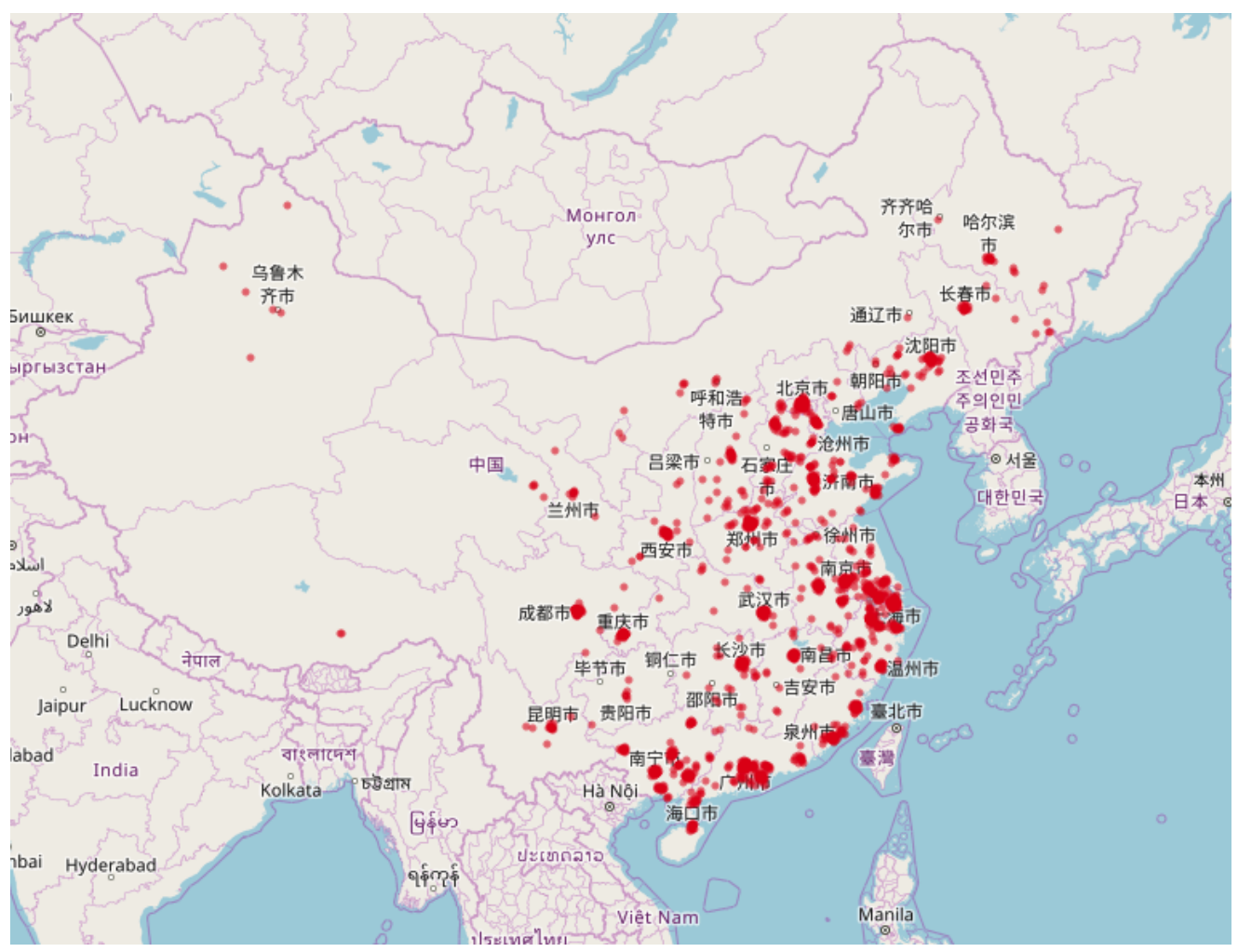




\title{
F Full survey - English (Chinese version available upon re- quest)
}

\author{
Introduction \\ Thank you for your participation! This is a political science survey overseen by Professor Sven Oskarsson as the \\ primary researcher for which Uppsala University is the principal organizer.
}

Your participation makes a valuable contribution to academic research. It is therefore important that you read all questions closely and answer them truthfully. If you prefer to not to respond to a question, please choose the alternative "prefer not to answer". Completing the questionnaire should take approximately 10 minutes. Participation in this survey is voluntary and unauthorized persons will not be given access to your responses. If at any time you wish to quit the survey you may do so by navigating away from this site or closing your browser window.

If you wish to participate please click Next below. If you do not wish to participate please navigate away from this site or close your browser window.

Sven Oskarsson

Department of Government

Uppsala University

sven.oskarsson@statsvet.uu.se

[University logo]

1. Which year were you born? [roll down list]

2. Gender: [Man/Woman/Prefer not to answer]

3. What is your ethnicity? [Han/Mongol/Manchurian/Hui/Tibetan/Zhuang/Other/Prefer not to answer]

4. In which region of China do you live? [roll down list]

5. In which city or town do you currently live? [blank box]

6. What is your current hukou status? [Urban/Rural/None]

Condition: if None is selected: Skip to end of block

7. Do you have hukou in the city or town where you currently live? [Yes/No]

8. What is your highest level of education? [No education/Primary school/Junior high school/High school (including secondary school)/Junior College/University Bachelor/Master and above/Other]

9. What is your annual income in Chinese Yuan? [Below 50.000/Between 50.000 and 100.000/Between 100.000 and 200.000/Above 200.000 yuan/Prefer not to answer]

10. Are you working for the government or public institution, for private business or industry, or for a private nonprofit organization? [Government and state-owned enterprises and institutions/Private enterprises/Private non-profit organizations/Not working/Prefer not to answer]

11. Do you have any children? [0/1/2/3/3 or more/Prefer not to answer]

12. What is your political affiliation? [Member of the Party (CCP)/Not a member/Prefer not to answer]

13. What is your main source of information? [Radio/TV/Print newspapers/The Internet (including mobile)/Other]

14. What is your father's highest level of education (including currently enrolled)? [No education/Primary school/Junior high school/High school (including secondary school)/Junior College/University Bachelor/Master and above/Other]

15. What is your mother's highest level of education (including currently enrolled)? [No education/Primary school/Junior high school/High school (including secondary school)/Junior College/University Bachelor/Master and above/Other] 
16. What is your fathers political affiliation? [Member of the Party (CCP)/Not a member/Prefer not to answer]

17. What is your mothers political affiliation? [Member of the Party (CCP)/Not a member/Prefer not to answer]

18. How much do you agree with the following statement, Even if parents demands are unreasonable, children still should do what they ask. [Strongly disagree/Somewhat disagree/Somewhat agree/Strongly agree/Dont know/Dont wish to say]

19. How much do you agree with the following statement, Being a student, one should not question the authority of ones teacher. [Strongly disagree/Somewhat disagree/Somewhat agree/Strongly agree/Dont know/Dont wish to say]

20. How much do you agree with the following statement, For the sake of the family, the individual should put his or her personal interests second. [Strongly disagree/Somewhat disagree/Somewhat agree/Strongly agree/Dont know/Dont wish to say]

21. Here we would like to confirm that you have read all the questions closely. Please select No from the list below, whether or not it is true for you. Do you think it is has been interesting to participate in this survey? [Yes/No] List experiments: How many of the above statements do you agree with? (items in bold only presented to treatment group, see figure 1)

22. Confidence

Generally speaking, most people cannot be trusted.

We should focus less on the economy and more on the environment.

The government is like a parent and should tell us what to do.

I have confidence in the national government.

The government is the employee of the people and should do things according to the wishes of the people.

23. System

It is important to follow religious norms and ceremonies.

Private ownership of business should be increased.

Our system of government is better than any other that I can think of.

Women make equally good political leaders as men.

When jobs are scarce, men should have more right to a job than women.

24. Corruption

Air pollution is one of the most important problems in our country.

Overall, the quality of life was better 30 years ago.

Overall, our country is going in the right direction.

The government is doing its best to crack down on corruption and root out bribery.

Economic progress is more important than protecting the environment.

25. Censorship

People can only get rich at the expense of others.

The government should have the right to prevent the media from publishing things that might be politically destabilizing.

I consider myself capable of participating in politics.

It is reasonable for students to pay tuition for university education.

The economic situation of my family was better a few years ago than it is today.

Direct questions

26. Do you agree with the following statement, I have confidence in the National Government? [Yes/No/Prefer not to answer] 
27. Do you agree with the following statement, The government doing its best to crack down on corruption and root out bribery?? [Yes/No/Prefer not to answer]

28. Do you agree with the following statement, Our system of government is better than any other that I can think of.? [Yes/No/Prefer not to answer]

29. Do you agree with the following statement: The Government should have the right to prevent the media from publishing things that might be politically destabilizing. [Yes/No/Prefer not to answer]

30. Who do you think has commissioned this investigation? [The Government or government agency/An independent research institute or university/A Private Enterprise/Other/Do not know]

31. This is the last question of the survey and here we would like to confirm that you have read all the questions closely. Please select No from the list below, whether or not it is true for you. Do you think it is has been interesting to participate in this survey? [Yes/No]

32. Thank you for taking the time to participate in this survey. Your reply has been recorded. [End] 